\title{
Rechtstreeks verwijzen door de jeugdarts bij verdenking op heupdysplasie: het perspectief van ouders
}

\author{
Marjon Witting, ${ }^{1}$ Magda M. Boere-Boonekamp, ${ }^{1}$ Margot A.H. Fleuren, ${ }^{2}$ Ralph J.B. Sakkers, ${ }^{3}$ Maarten J. IJzerman ${ }^{1}$
}

Doel: Rechtstreeks verwijzen door de jeugdarts naar de tweede lijn lijkt zinvol bij verdenking op heupdysplasie. Screening op heupdysplasie vindt plaats door lichamelijk onderzoek en de identificatie van risicofactoren. Echografische screening blijkt medisch en economisch gezien te leiden tot betere uitkomsten. Als onderdeel van een studie naar de haalbaarheid van implementatie van echografische screening in Nederland is onderzocht hoe ouders het verwijstraject beoordelen afhankelijk van de manier waarop zij naar de orthopaedisch chirurg zijn verwezen - rechtstreeks of via de huisarts - bij verdenking op heupdysplasie. Methode: Een vragenlijst is ontwikkeld om de ervaring van ouders die verwezen zijn te meten. In totaal is de vragenlijst gestuurd naar 355 ouders van kinderen die verwezen zijn tussen januari 2008 en november 2008. Resultaten: De respons op de vragenlijst was $46,5 \%$. Ouders waren meer tevreden wanneer zij door de jeugdarts rechtstreeks waren verwezen dan wanneer dat via de huisarts plaatsvond. De tijd tussen de verwijzing en de eerste afspraak bij de orthopaedisch chirurg was korter als kinderen rechtstreeks werden verwezen. Tot slot waren ouders meer tevreden als zij het verwijstraject als niet stressvol ervoeren en als het traject soepel verliep. Conclusie: Gebaseerd op de perceptie van ouders, geeft dit onderzoek een eerste indicatie dat, met inachtneming van een aantal belangrijke randvoorwaarden, rechtstreeks verwijzen in het geval van heupdysplasie wenselijk is.

Trefwoorden: heupdysplasie, rechtstreeks verwijzen, echografische screening, tevredenheid patiënten, jeugdgezondheidszorg

\begin{abstract}
INLEIDING
In de jeugdgezondheidszorg wordt bijna 20\% van alle kinderen verwezen voor aanvullend onderzoek wegens verdenking op of uitsluiting van heupdysplasie ${ }^{1}$ en het is daarmee de belangrijkste verwijsreden vanuit het consultatiebureau. ${ }^{2}$ Deze kinderen worden in eerste instantie naar de huisarts verwezen die in de meeste gevallen de ouders doorverwijst naar de specialist. Deze verwijsstructuur sluit aan bij de rol van de huisarts als poortwachter, behandelend arts en gezinsarts. ${ }^{3}$ Er bestaat echter discussie over de meerwaarde van een consult door de huisarts bij gezonde kinderen die verwezen zijn op basis van een screeningsonderzoek door een jeugdarts, zoals de screening op heupdysplasie. Rechtstreeks verwijzen naar de orthopaedisch chirurg bij heupdysplasie lijkt zinvol,
\end{abstract}

\footnotetext{
${ }^{1}$ Vakgroep Health Technology and Services Research, Universiteit Twente, Enschede

2 Afdeling Child Health, TNO, Leiden

${ }^{3}$ Afdeling Orthopaedie, Universitair Medisch Centrum Utrecht, Utrecht
}

omdat hiermee een aantal belangrijke voordelen behaald kan worden, zoals tijdsbesparing voor ouders en verbeterde gegevensuitwisseling tussen medisch specialisten en jeugdarts. ${ }^{3}$

Voorwaarden voor rechtstreeks verwijzen naar de tweede lijn door de jeugdarts, geformuleerd naar aanleiding van een pilot in Noord-Brabant, zijn dat de arts minstens één jaar werkzaam is in de jeugdgezondheidszorg, dat gewerkt wordt op basis van richtlijnen of protocollen en dat er afspraken zijn over de onderlinge gegevensuitwisseling binnen de keten. ${ }^{3}$ Om optimale zorg voor het kind te bevorderen is recent een Landelijke Eerstelijns Samenwerkings Afspraak (LESA) Dysplastische HeupOntwikkeling ontwikkeld. ${ }^{4}$ Deze LESA, opgesteld door een werkgroep van de vereniging Artsen Jeugdgezondheidszorg Nederland (AJN) en het Nederlands Huisartsen Genootschap (NHG), geeft richtlijnen voor de samenwerking en suggesties voor werkafspraken tussen jeugdarts en huisarts in het geval van rechtstreekse verwijzing naar de specialist bij verdenking op heupdysplasie. 
De screening op heupdysplasie vindt plaats door herhaaldelijk lichamelijk onderzoek en de identificatie van risicofactoren. In veel Duitstalige landen wordt echografie toegepast om heupdysplasie op te sporen. ${ }^{5}$ In 1998 en 1999 is in Nederland een onderzoek uitgevoerd naar de effectiviteit van echografische screening vergeleken met de gebruikelijke screening. Hieruit bleek dat echografische screening van kinderen op de leeftijd van drie maanden leidt tot minder gemiste gevallen en relatief weinig verwijzingen. ${ }^{6} \mathrm{Be}$ halve klinische uitkomstmaten van screening op heupdysplasie zijn ook minder objectieve maten, zoals tevredenheid van de ouders met de screening, van belang. ${ }^{7}$ De tevredenheid van patiënten is een belangrijke determinant voor de kwaliteit van de geleverde zorg $^{8-9}$ en heeft invloed op het gedrag van patiënten, zoals het naleven van een aanbevolen behandeling. ${ }^{9-10}$

Het doel van dit onderzoek was inzicht te krijgen in de ervaring en tevredenheid van ouders met het verwijstraject bij een afwijkende screeningsecho. Specifiek wordt ingegaan op verschillen tussen ouders die via de huisarts naar de orthopaedisch chirurg zijn verwezen en ouders die rechtstreeks zijn verwezen. Dit onderzoek was onderdeel van een grotere vervolgstudie naar de haalbaarheid en kosteneffectiviteit van implementatie van echografische screening op heupdysplasie in Nederland. In deze studie kregen alle ouders van pasgeborenen in de regio's Utrecht en Salland de mogelijkheid om, naast het reguliere lichamelijke onderzoek, een heupecho te laten maken tijdens een extra consult. In totaal zijn, van november 2007 tot en met april 2009, 4099 kinderen echografisch gescreend. Dit vond plaats op de leeftijd van drie maanden en werd uitgevoerd door speciaal opgeleide jeugdartsen, jeugdverpleegkundigen en radiologisch laboranten op de consultatiebureaus. Alle kinderen met een afwijkende screeningsecho zijn naar de huisarts of orthopaedisch chirurg verwezen voor verdere diagnostiek en eventuele behandeling. In overleg met de grootste zorgverzekeraar zijn alle kinderen in Salland rechtstreeks verwezen, waarbij huisartsen een kopie van de verwijsbrief ontvingen. In Utrecht werden kinderen eerst naar de huisarts verwezen.

\section{METHODE}

\section{Deelnemers en procedure}

Alle ouders $(N=355)$ van kinderen die in de periode januari 2008 tot en met november 2008, al dan niet rechtstreeks, zijn verwezen naar de orthopaedisch chirurg hebben drie tot vier maanden later per post een vragen- lijst ontvangen. Het betrof 259 ouders in Salland en 96 ouders in Utrecht. De termijn van drie tot vier maanden is aangehouden om zeker te zijn dat ouders de orthopaedisch chirurg reeds bezocht hadden en wisten of hun kind behandeld zou worden. Na twee weken is een herinneringsbrief verstuurd.

\section{Vragenlijst}

De vragenlijst is ontwikkeld samen met jeugdgezondheidszorgdeskundigen en een implementatiedeskundige. Daarnaast is deze gebaseerd op eerder onderzoek naar de ervaring van ouders met rechtstreeks verwijzen. ${ }^{3}$ Via zeven items konden ouders aangeven hoe zij het verwijstraject hebben ervaren (vijfpuntsschaal lopend van "helemaal mee oneens" tot "helemaal mee eens") (Tabel 1). Door middel van een vijfpuntsschaal is gevraagd hoe praktisch ouders het verwijstraject vonden. Aan ouders die via de huisarts zijn verwezen is gevraagd of ze liever rechtstreeks naar het ziekenhuis waren verwezen en aan ouders die rechtstreeks zijn verwezen is gevraagd of ze liever via de huisarts waren verwezen. Tot slot konden ouders door middel van een rapportcijfer lopend van 1 tot 10 aangeven wat ze van het verwijstraject vonden.

\section{Analyse}

T-toetsen (tweezijdig) voor onafhankelijke steekproeven zijn uitgevoerd om verschillen tussen wel/niet rechtstreeks verwijzen te analyseren wat betreft de tevredenheid van ouders en de tijd tussen verwijzing en het eerste consult bij de orthopaedisch chirurg. Chi-kwadraattoetsen en Fisher's Freeman Halton exact toetsen (tweezijdig) voor categorische variabelen zijn gebruikt om verschillen tussen wel/niet rechtstreeks verwijzen te toetsen met betrekking tot de ervaring van ouders. Met behulp van een univariate variantieanalyse (ANCOVA) is onderzocht welke factoren de tevredenheid van ouders over het verwijstraject bepaalden.

\section{Resultaten}

\section{Deelnemers}

De vragenlijst is teruggestuurd door 165 ouders (respons $46,5 \%)$. Acht vragenlijsten zijn niet of niet volledig ingevuld en één ouder had het advies van verwijzing niet opgevolgd. De resultaten van vijftien ouders zijn niet meegenomen, omdat zij niet volgens het protocol binnen de thuiszorgorganisaties zijn verwezen (zes kinderen via de huisarts verwezen in Salland; negen kinderen rechtstreeks verwezen in Utrecht). Uiteindelijk waren 141 vragenlijsten bruikbaar (respons 39,7\%). Hiervan zijn 


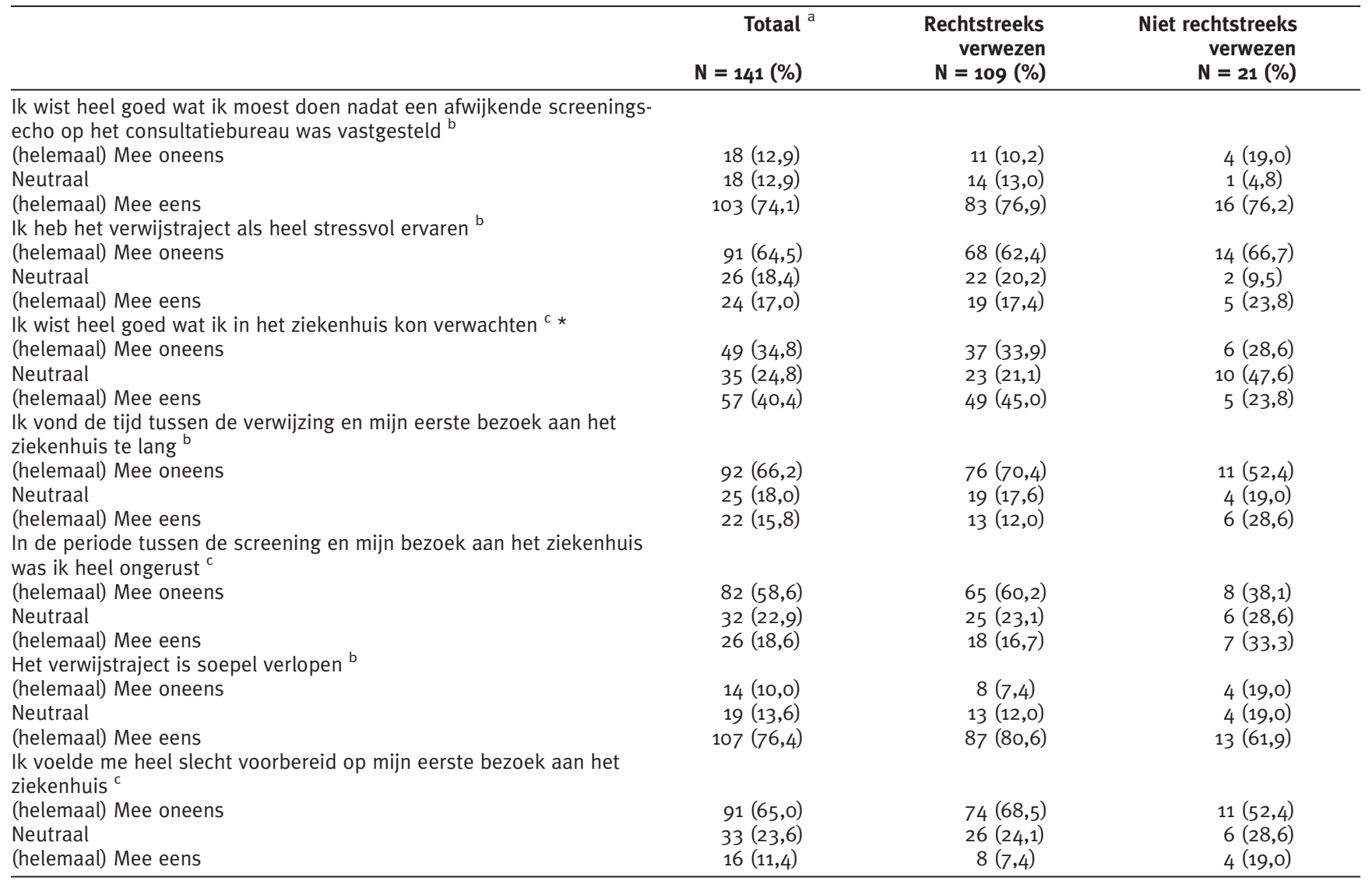

* $\mathrm{p} \leq 0,05$.

a De totalen komen niet overeen met de som van rechtstreeks en niet rechtstreeks verwezen, omdat van elf ouders de informatie over de verwijzing niet beschikbaar was.

b Uitgevoerd met een Fisher's Freeman Halton toets voor categorische variabelen.

${ }^{\mathrm{c}}$ Uitgevoerd met een Chi-kwadraattoets voor categorische variabelen.

vragenlijsten ingevuld door 21 van de 96 ouders uit Utrecht (respons $21,9 \%$ ) en 120 van de 259 ouders uit Salland (respons 46,3\%).

Van elf ouders is niet bekend of ze wel of niet rechtstreeks zijn verwezen. Van de overgebleven 130 ouders zijn 109 ouders $(83,8 \%)$ rechtstreeks verwezen en 21 ouders $(16,2 \%)$ via de huisarts. Iets minder dan de helft $(48,2 \%)$ van alle verwezen kinderen is behandeld, waarvan $49,6 \%$ in Salland en $45,0 \%$ in Utrecht $\chi^{2}(1, N=139)$ $=0,14, p=0,71$. Twee ouders $(1,4 \%)$ weten (nog) niet of hun kind behandeld is of zal worden.

\section{Evaluatie verwijstraject}

Ouders evalueerden het verwijstraject gemiddeld met een rapportcijfer van $7,24(S D=1,89)$. Ouders die rechtstreeks zijn verwezen gaven gemiddeld een 7,51 $(S D=$ $1,78)$ en ouders die via de huisarts zijn verwezen gaven gemiddeld een 6,31 $(S D=2,25)$. Dit verschil was significant $t(126)=2,71, p<0,01$, en toont een relatie aan van $r$ $=0,23$.

De tijd tussen de verwijzing en het eerste bezoek aan het ziekenhuis was gemiddeld twee en een halve week $(M$ $=2,52, S D=1,48)$. Ouders die rechtstreeks zijn verwezen bezochten na iets minder dan twee en een halve week het ziekenhuis $(M=2,33, S D=1,30)$ en ouders die via de huisarts zijn verwezen na drie weken $(M=3,00, S D=$ $1,84)$. Dit verschil was significant $t(127)=-2,00, p=0,05$. Alle ouders die via de huisarts zijn verwezen waren liever rechtstreeks verwezen en $90 \%$ van de ouders die rechtstreeks zijn verwezen waren liever niet eerst via de huisarts gegaan. Van de ouders die rechtstreeks zijn verwezen vond $87,7 \%$ het traject praktisch, tegenover 5,0\% van de ouders die niet rechtstreeks zijn verwezen. In Tabel 1 staan de resultaten van de vragen met betrekking tot de ervaring van ouders weergegeven. In verband met de lage aantallen zijn de resultaten gecomprimeerd tot drie antwoordcategorieën. Het item 'Ik wist heel goed wat $\mathrm{ik}$ in het ziekenhuis kon verwachten', bleek significant te verschillen tussen ouders die wel/niet rechtstreeks zijn verwezen $\chi^{2}(2, N=130)=6.93, p=0,03$. Nadere analyses lieten zien dat ouders die rechtstreeks zijn verwezen het vaker met deze stelling eens zijn en minder vaak neutraal antwoorden dan ouders die niet-rechtstreeks zijn verwezen.

In Tabel 2 staan de resultaten van de ANCOVA weergegeven. De mate waarin ouders het verwijstraject als stressvol ervoeren bleek van invloed op de tevredenheid. Naarmate ouders het verwijstraject als minder stressvol ervoeren, waren zij meer tevreden $t(117)=1,95, p=0,05$. 
Ook was er een positief effect van de mate waarin ouders vonden dat het verwijstraject soepel verliep op de tevredenheid. Ouders die vonden dat het verwijstraject soepel verliep waren meer tevreden dan ouders die het niet met deze stelling eens waren $t(117)=-5,87, p<0,01$. De tijd tussen de verwijzing en het eerste bezoek aan de orthopaedisch chirurg en of het kind wel of niet behandeld is, hadden geen invloed op de tevredenheid.

\section{DISCUSSIE}

Deze studie toont aan dat ouders meer tevreden zijn als zij rechtstreeks vanuit het consultatiebureau naar de orthopaedisch chirurg zijn verwezen dan wanneer zij eerst de huisarts bezochten in het geval van een afwijkende screeningsecho. Alle ouders die via de huisarts zijn verwezen waren liever rechtstreeks verwezen en andersom was de meerderheid van de rechtstreeks verwezen ouders liever niet via de huisarts gegaan. Ouders die rechtstreeks zijn verwezen vonden dit traject bovendien praktischer dan ouders die via de huisarts zijn verwezen. Dit komt overeen met de resultaten uit eerder onderzoek waarin werd gevonden dat $93 \%$ van alle ouders het onpraktisch vond om via de huisarts te worden verwezen. ${ }^{3}$

Het rechtstreeks verwijzen leidde er toe dat ouders een paar dagen eerder in het ziekenhuis terecht konden. Een extra bezoek aan de huisarts is mogelijk de oorzaak van dit verschil. Het is van belang om de lengte tussen verwijzing en het eerste bezoek aan het ziekenhuis te beperken, zodat enerzijds een behandeling zo snel mogelijk ingezet kan worden en anderzijds de negatieve gevoelens van ouders, zoals angst en bezorgdheid, te beperken. De lengte van de periode tussen verwijzing en het eerste bezoek aan de specialist had geen invloed op de tevredenheid van ouders.

Ouders waren meer tevreden als zij het verwijstraject niet stressvol vonden en als zij het verloop van het verwijstraject als soepel ervoeren. Praktisch gezien betekent dit dat de screener het begin van het verwijstraject zodanig moet faciliteren dat ouders op een prettige manier het traject ingaan, bijvoorbeeld door goede voorlichting over het gevonden resultaat. Romeijn ${ }^{11}$ benadrukt eveneens het belang van goede communicatie en overeenstemming met ouders over het probleem in het geval van een verwijzing vanuit de jeugdgezondheidszorg.
Eén van de beperkingen van dit onderzoek is dat het, om praktische redenen, niet mogelijk was ouders random toe te wijzen aan wel of geen rechtstreekse verwijzing. Dit betekent dat andere factoren, waaronder regionale ligging en socio-demografische verschillen tussen ouders, mogelijk ook van invloed kunnen zijn op enkele resultaten. Uit een meta-analyse blijkt echter dat socio-demografische kenmerken een minimale invloed hebben op de tevredenheid met gezondheidszorg. ${ }^{12}$ Daarnaast is het niet waarschijnlijk dat de organisatie waarin de screening plaatsvond de gevonden verschillen kan verklaren, aangezien zij de screening volgens een strikt protocol hebben uitgevoerd en ouders daarom dezelfde zorg hebben ontvangen. We verwachten dan ook dat de kans dat de gevonden verschillen in tevredenheid verklaard worden door andere kenmerken minimaal is en dat zij voornamelijk terug te voeren zijn op de procedure van doorverwijzing.

Een andere beperking van dit onderzoek is dat de groep kinderen die rechtstreeks is verwezen (Salland) veel groter is dan de groep kinderen die via de huisarts is verwezen (Utrecht). Hoewel de reproduceerbaarheid van de echoscreening voldoende is gebleken ${ }^{13-14}$ zijn er in deze studie mogelijk verschillen tussen screeners in het maken en interpreteren van echo's die ertoe hebben geleid dat het percentage verwijzingen in de ene regio groter is dan in de andere regio. Daarnaast zijn in Salland over de gehele onderzoeksperiode meer kinderen $(N=2370)$ gescreend dan in Utrecht $(N=1729)$, wat betekent dat de kans dat meer kinderen zijn doorverwezen in deze regio groter is. Tot slot is het mogelijk dat de prevalentie van heupdysplasie in de regio Salland inderdaad hoger is dan in Utrecht, bijvoorbeeld vanwege het familiair voorkomen van de aandoening.

De respons op het vragenlijstonderzoek in Utrecht, waar niet rechtstreeks is verwezen, was lager dan de respons in Salland. In eerder onderzoek werd gevonden dat mensen minder geneigd zijn om aan (vragenlijst)onderzoeken deel te nemen als zij minder tevreden zijn over de geleverde zorg. ${ }^{15-16}$ Dit kan betekenen dat het gevonden verschil in tevredenheid tussen wel/niet rechtstreeks verwezen kinderen mogelijk groter is dan in deze studie is gevonden. Een andere mogelijkheid die het verschil in respons kan verklaren zijn socio-demografische kenmer-

Tabel 2 Resultaten van ANCOVA met als afhankelijke variabele tevredenheid met het verwijstraject

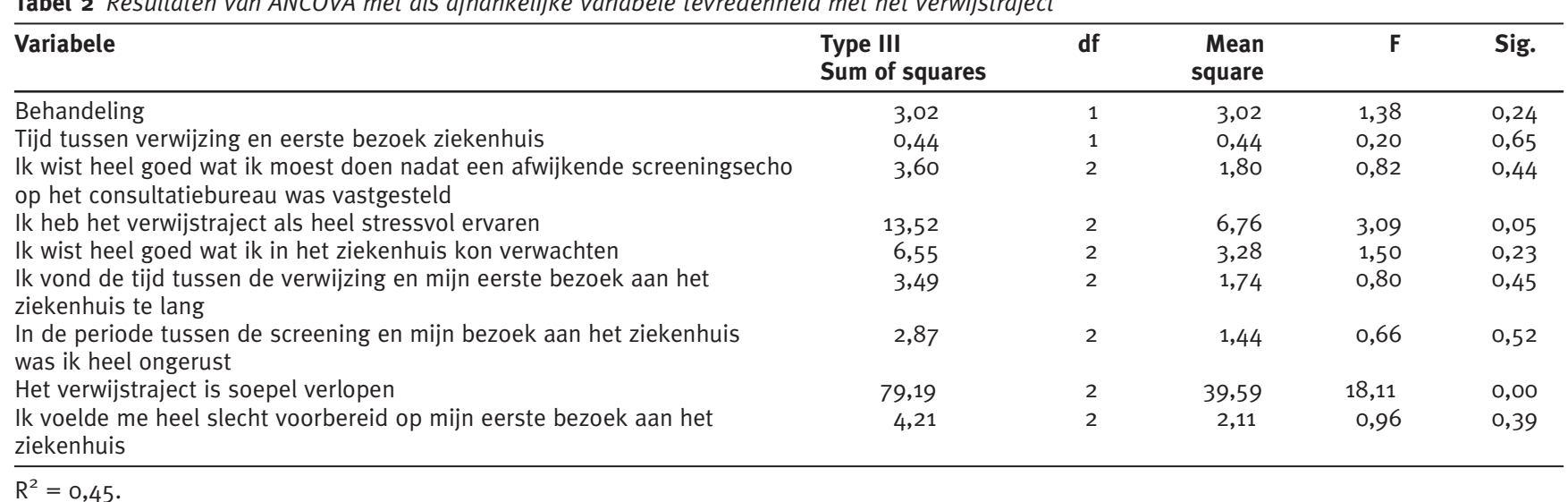


ken van de ouders. Zo wordt non-participatie aan onderzoeken onder andere geassocieerd met het hebben van een andere etniciteit en het wonen in een stedelijk gebied. ${ }^{17}$ Wellicht hebben taalproblemen in Utrecht ertoe geleid dat het voor ouders met een andere etniciteit moeilijk was de vragenlijst in te vullen. We moeten dan ook voorzichtig zijn met het generaliseren van de resultaten naar de gehele populatie, aangezien we geen inzicht hebben in de ervaringen van de niet-participanten.

Tot slot was de tijd tussen de verwijzing en de ontvangst van de vragenlijst drie tot vier maanden. Dit kan hebben geleid tot recall bias; ouders kunnen zich wellicht niet goed herinneren hoe het verwijstraject is verlopen. Het kan eveneens hebben geleid tot selectieve respons; ouders van kinderen waarbij geen behandeling is ingezet reageren mogelijk minder vaak, omdat het verwijstraject reeds is afgerond. Ouders van kinderen die nog in het behandeltraject zitten zullen mogelijk vaker reageren, omdat het voor hen nog geen afgesloten traject is.

Dit onderzoek laat zien dat, in de perceptie van ouders, rechtstreeks verwijzen bij verdenking op heupdysplasie de voorkeur heeft boven een verwijzing via de huisarts. Ouders zijn meer tevreden over dit traject en vinden het praktischer. Ook leidde het rechtstreeks verwijzen ertoe dat ouders een aantal dagen eerder in het ziekenhuis terecht konden voor aanvullend onderzoek. De gevonden resultaten geven een eerste indicatie dat rechtstreeks verwijzen wenselijk is in het geval van verdenking op heupdysplasie, wat in lijn is met eerder geformuleerde aanbevelingen. ${ }^{3}$ Vervolgonderzoek onder medisch specialisten, huisartsen en jeugdartsen moet meer inzicht geven in de wenselijkheid van en de voorwaarden voor het rechtstreeks verwijzen bij heupdysplasie. Bij eventuele toekomstige invoering van rechtstreeks verwijzen is het belangrijk dat monitoring van dit traject plaatsvindt. Als uitgangspunt voor de implementatie kan de LESA Dysplastische HeupOntwikkeling ${ }^{4}$ genomen worden, waarin randvoorwaarden voor (rechtstreekse) verwijzing zijn geformuleerd, zoals afspraken over de verwijsroute voor beeldvormend onderzoek, de (terug)rapportage en borging van het zorgtraject.

\section{ABSTRACT}

Direct referral by the child health care physician in case of suspicion of developmental dysplasia of the hip: the perspective of parents

Aim Direct referral by the child health care (CHC) physician to secondary care seems useful in case of suspicion of developmental dysplasia of the hip (DDH). Screening for $\mathrm{DDH}$ is based on physical examination and the identification of risk factors. Ultrasound (US) screening seems to lead to better medical and economic outcomes. As part of a study into the feasibility of implementation of US screening in the Netherlands, we studied how parents evaluated the referral process depending on the way they were referred to the orthopaedic surgeon -directly or via the general practitioner (GP)- in case of a suspicion of DDH. Methods A questionnaire was developed to evaluate the experience of parents of infants who were referred. A total of 355 parents of infants who were referred between January 2008 and
November 2008 received the questionnaire. Results The response rate was $46.5 \%$. Parents were more satisfied if they were directly referred by the CHC physician instead of indirectly via the GP. The time between referral and the first appointment with the orthopaedic surgeon was shorter if infants were directly referred. Finally, if parents evaluated the referral process as not stressful and if it proceeded fluently they were more satisfied. Conclusion Based on the perception of parents, this study provides a first indication that, with taking into consideration some important preconditions, direct referral to secondary care in the case of DDH is desirable.

Keywords: developmental dysplasia of the hip, referral, ultrasonography, patient satisfaction, child health services

\section{LITERATUURLIJST}

1. Boere-Boonekamp MM, Kerkhoff THM, Schuil PB, Zielhuis GA. Early detection of developmental dysplasia of the hip in the Netherlands: the validity of a standardized assessment protocol in infants. Am J Public Health 1998;88:285-8.

2. Buiting E, Pijpers FIM. Verwijzingen vanuit het consultatiebureau; en wat daarna? Tijdschr JGZ 2002;34:114-7.

3. Buiting AMT, Verkerk PH, Wagenaar-Fischer MM, HiraSing RA. Verslag Project rechtstreeks verwijzen van de jeugdgezondheidszorg naar de 2e lijn. Leiden: TNO Kwaliteit van Leven, 2006.

4. Boere-Boonekamp MM, Klein Ikkink AJ, Sleuwen BE van et al. Landelijke Eerstelijns Samenwerkings Afspraak Dysplastische HeupOntwikkeling. Huisarts Wet 2010;53:S21-4.

5. Dorn U, Neumann D. Ultrasound for screening developmental dysplasia of the hip: a European perspective. Curr Opin Pediatr 2005; 17:30-3.

6. Roovers EA, Boere-Boonekamp MM, Castelein RM, Zielhuis GA, Kerkhoff TH. Effectiveness of ultrasound screening for developmental dysplasia of the hip. Arch Dis Child Fetal Neonatal Ed 2005;90:F25-30.

7. Hall DMB. The role of the routine neonatal examination. BMJ 1999;318:619-20.

8. Donabedian A. Evaluating the quality of medical care. Milbank Mem Fund Q 1966;44:166-206.

9. Donabedian A. The Lichfield Lecture. Quality assurance in health care: consumers' role. Qual Health Care 1992;1:247-51.

10. Pascoe GC. Patient satisfaction in primary health care: a literature review and analysis. Eval Program Plann 1983;6:185-210.

11. Romeijn MA. Wijzer verwijzen. Een Delphi onderzoek naar het verwijstraject binnen de Jeugdgezondheidszorg in Amsterdam. Tijdschr JGZ 2002;34:74-6.

12. Hall JA, Dornan MC. Patient sociodemographic characteristics as predictors of satisfaction with medical care: a meta-analysis. Soc Sci Med 1990;30:811-8.

13. Roovers EA, Boere-Boonekamp MM, Geertsma TSA, Zielhuis GA, Kerkhoff AHM. Ultrasonographic screening for developmental dysplasia of the hip in infants. Reproducibility of assessments made by radiographers. J Bone Joint Surg 2003;85B:726-30.

14. Ramwadhdoebe S, Sakkers RJB, Uiterwaal CSPM, Boere-Boonekamp MM, Beek FJA. Evaluation of a training program for general ultrasound screening for developmental dysplasia of the hip in preventive child health care. Pediatr Radiol 2010;40: 1634-9. 
15. Perneger TV, Chamot E, Bovier PA. Nonresponse bias in a survey of patient perceptions of hospital care. Med Care 2005; 43:374-80.

16. Mazor KM, Clauser BE, Field T, Yood RA, Gurwitz JH. A demonstration of the impact of response bias on the results of patient satisfaction surveys. Health Serv Res 2002;37:1403-17.

17. Haunberger $S$. The effects of interviewer, respondent and area characteristics on cooperation in panel surveys: a multilevel approach. Qual Quant 2010;44:957-69.

\section{CORRESPONDENTIEADRES}

Marjon Witting, Vakgroep Health Technology and Services Research, Faculteit Management en Bestuur, Universiteit Twente, Postbus 217, 7500 AE Enschede, tel. 053-4894483, e-mail: m.witting@alumnus.utwente.nl 